\title{
Research of Lightweight Composite Automobile Wheel
}

\author{
Yue Bao, Xiaoyu Zhao \\ School of Automotive Engineering, Shanghai University of Engineering Science, Shanghai, China \\ Email: 843353028@qq.com
}

How to cite this paper: Bao, Y. and Zhao, X.Y. (2017) Research of Lightweight Composite Automobile Wheel. World Journal of Engineering and Technology, 5, 675-683. https://doi.org/10.4236/wjet.2017.54056

Received: September 18, 2017

Accepted: October 31, 2017

Published: November 3, 2017

Copyright $\odot 2017$ by authors and Scientific Research Publishing Inc. This work is licensed under the Creative Commons Attribution International License (CC BY 4.0).

http://creativecommons.org/licenses/by/4.0/

\section{c) (i) Open Access}

\begin{abstract}
Composite materials are widely used in automobiles because of their small proportion, large modulus and high strength. In this paper, carbon fiber-epoxy (T300/5222) composite material is used to design the composite automobile wheel hub according to the general principle of laminated plate design. And the hub layer is finished with hypermesh 14.0. The stress and strain of the hub can be analyzed by Hyperworks 14.0 according to the three kinds of conditions. Then the maximum stress layer is found out and the strength is checked. The composite wheel hub is compared with the same aluminum alloy hub. The results showed that composite materials of hub can be achieved in hub strength requirements. Because its ultimate stress is bigger than Aluminum Alloy of hub, obviously the strength of composite hub is higher than the Aluminum Alloy of hub. Because of the smaller strain, the impact of performance is better. The composite wheel hub reduces the weight of $11.3 \%$.
\end{abstract}

\section{Keywords}

Automobile Hub, Composite Material, Hyperworks 14.0

\section{Introduction}

Lightweight is the current trend of the development of the automobile industry, lighter quality means lower fuel consumption and less emission. The use of light weight materials can help reduce vehicle weight and improve fuel economy. World Aluminum Association report pointed out that the quality of the car itself reduced by $10 \%$, fuel consumption can be reduced by $6 \%$ to $8 \%$ and emissions drop 4\% [1]. Currently, an important way of the Car lightweight is to use lightweight materials such as aluminum, magnesium, plastic, fiberglass or carbon fiber composites. The wheel is used as a rotating part. Its lightweight effect 
is equivalent to about 1.5 times the non-rotating parts. [2] Therefore, as an important part of the car, wheel lightweight is the trend of lightweight development.

At present, domestic and foreign research on Composite hubs is rare. So there is still a lot of room for this research. Xiaoyin Wang and Xiandong Liu et al. [3] based on hyper works software used OptiStruct module on the thermoplastic composite hub topology optimization, simultaneously with RADIOSS solver for intensity simulation. The results show that the composite wheel based on the maximum principal stress failure criterion has a greater margin of safety and reduces $22.3 \%$ compared with the aluminum wheel; Bingpeng Li and Zeyu Sun et al. [4] use the optimization of hot-pressing cans made of composite hubs to meet the impact of $600 \mathrm{~kg}$ static load in a $13^{\circ}$ impact test; Yue Pan and Xiandong Liu et al. [5] use the long glass fiber reinforced thermoplastic composites as material, combined with Moldflow, Digimat, Abaqus and other software to simulate the strength of composite hub under radial load. The results show that the anisotropy of the material has great influence on the stress and strain. Currently, it rarely reports the study of wheel force under three kinds of conditions. Therefore, the analysis of composite wheel under three conditions has great reference value for composite wheel.

\section{Analysis on the Condition of Automobile Wheel}

The three conditions chosen in this paper are mainly based on national standards to determine, respectively, under radial load, under the bending load, under the impact load. GB/T5334-2005 "passenger car wheel performance requirements and experimental methods" [6] requirements of steel wheels and light alloy wheels must be sold before the radial fatigue test and bending fatigue test. GB/T15704-2012 "road vehicle light alloy wheel impact test method" [7] requirements of light alloy wheels also through the impact test. There is no test standard for composite wheels, and the composite wheels studied in this paper will refer to light alloys as a reference standard.

\subsection{Radial Load Condition of Wheel}

In the radial fatigue test of the wheel, the wheel is rotated to withstand the constant radial load applied by the drum, and the load direction is connected along the center of the wheel and the drum. Therefore, according to the working principle of wheel radial load fatigue test, the wheel structure is fully restrained on the surface of the mounting disk and the bolt hole. The radial load of the cosine function distribution is applied over a certain range of rims. And exert an inflation pressure on the entire outer rim. In this paper, the tire pressure is 3 Bar.

According to the national standard with the following formula to determine the radial load, the unit is $N$ :

$$
F_{r}=F_{v} K
$$

where: $F_{v}$ is the maximum vertical static load on the wheel specified by the wheel or the automobile manufacturer or the rated load of the wheel, the unit is 
$N ; K$ is the reinforcement test coefficient.

Because the stress distribution of the rim and the tire contact is taken into account. When a radial load is applied to the hub, it is necessary to convert the cosine load into force, as follows [8]:

$$
P=\frac{F_{r}\left(\pi^{2}-B^{2}\right) \cos \left(\frac{a}{B} \pi\right)}{2 R L B \pi \cos \frac{B}{2}}
$$

where: $R$ represents the radius, $L$ represents the width, represents the angle, and $B$ is the designated area angle.

\subsection{Wheel Bending Load Conditions}

In bending fatigue tests, full restraint is applied to the inside of the rim and eccentric force is applied to the hub at the other end of the shaft. The finite element analysis is simplified. Center to establish nodes. The node and the hub center for rigid connection. The bending of the nodes is applied.

Press the following formula determine the bending moment $\mathrm{M}$ :

$$
M=(\mu R+d) F_{v} S
$$

where: $\mu$ is the coefficient of friction, $R$ is the static load radius of the tire, $\mathrm{d}$ is the offset, $F_{v}$ is the maximum vertical static load on the wheel specified by the wheel or the automobile manufacturer or the rated load of the wheel.

\subsection{Impact Load Conditions}

The impact test is a transient response kinetic problem. In the process, the punch falls free and contacts the tire first, than touching the hub edge. In the whole process, Tires will be deformed. It is Involved a problem of energy absorption.

In order to simplify the problem, the punch from a certain height free fall impact of the wheel of this dynamic problem into a static problem. It can be based on momentum conservation that is equivalent to a force $F$. The action time is $t_{0}$. $F$ is the time that can be calculated according to the following formula:

$$
F=D v_{0} / t_{0}
$$

among them, $D$ is the punch quality, $v_{0}=\sqrt{2 g H}, g$ is the acceleration of gravity, $H$ is the punch height.

$$
D v=\int_{0}^{t_{0}} F_{\max } \sin \left(\pi t / t_{0}\right) \mathrm{d} t
$$

among them: $v=\sqrt{2(1-\eta) g H}, \quad \eta$ is the absorption of energy coefficient, about $20 \%$. On the right side of the Formula (5) can be obtained:

$$
F_{\max }=\frac{\pi}{2} D \cdot \sqrt{2(1-\eta) g H} / t_{0}
$$

Shang et al. [9] found that punch and flange from beginning to contact and at 
$34.5 \mathrm{~ms}$, the drop velocity is zero and the stress is maximum. So it is considered that the punch and wheel contact time is about $70 \mathrm{~ms}$.

\section{Pavement Structure Design and Finite Element Analysis of Composite Wheel}

The composite laying design generally arranges the fiber orientation according to the load distribution to maximize the use of fiber bearing the direction or The stiffness of the structure is obtained by the design of laying "cutting". The laminate design generally takes into account the principles: 1) the general laminated board designed to balance the symmetric laminated plate, which if there is a single layer $-45^{\circ}$, there should be $+45^{\circ}$ with its symmetry; 2) In order to simplify the workload, bear the in-plane load laminates are mostly $0^{\circ}, 90^{\circ}$ and $\pm 45^{\circ}$ and other four laying direction, while trying to separate them from each other.

\subsection{Composite Wheel Pavement Design}

The materials used in this paper are carbon fiber/epoxy (T300/5222) composites. The mechanical properties of the Table 1 below. The laying of the wheel is mainly $\left[0^{\circ} / 45^{\circ} / 90^{\circ} /-45^{\circ}\right]_{s}(s=6)$. Pavement direction wheel axle. The pavement is 24 layers. Each layer thickness is $1 \mathrm{~mm}$. After the laying of the wheel compared to the weight of aluminum alloy wheels to reduce the $11.3 \%$.

The boundary conditions and loads on the hub when the reference to the front of the wheel of the working conditions analysis. In order to form a contrast, in this paper, the same conditions of the aluminum alloy wheels for finite element analysis. Aluminum alloy material parameters, Elastic Modulus $E=7 \times 10^{4} \mathrm{MPa}$, density $\rho=2.7 \times 10^{9} \mathrm{t} / \mathrm{mm}^{3}$, Poisson's ratio $v=0.3$.

\subsection{Tsai-Wu Tensor Criterion}

The strength check criteria chosen in this paper is a combination of multiple intensity criteria proposed by Tsai-Wu in the form of tensor. It is assumed that the damaged surface in the stress space has the following form:

$$
F_{i} \sigma_{i}+F_{i j} \sigma_{i} \sigma_{j}<1
$$

In the formula, the coefficients $F_{i}$ and $F_{i j}$ are called the strength parameters of the stress space. In the plane stress state, $i, j=1,2,6$.

Simplify:

$$
F_{11} \sigma_{1}^{2}+2 F_{12} \sigma_{1} \sigma_{2}+F_{22} \sigma_{2}^{2}+F_{66} \tau_{12}^{2}+F_{1} \sigma_{1}+F_{2} \sigma_{2}<1
$$

among them

Table 1. Basic mechanical properties of composites.

\begin{tabular}{lcccccccccccc}
\hline $\begin{array}{c}\text { Compound } \\
\text { material }\end{array}$ & $v_{f}$ & $\rho /\left(\mathrm{kg} / \mathrm{m}^{3}\right)$ & $E_{1} / \mathrm{GPa} E_{2} / \mathrm{GPa}$ & $v_{1}$ & $G_{12} / \mathrm{GPa} X_{t} / \mathrm{MPa} X_{d} / \mathrm{MPa} Y_{t} / \mathrm{MPa}$ & $Y_{d} / \mathrm{MPa}$ & $S / \mathrm{MPa}$ \\
\hline $\mathrm{T} 300 / 5222$ & 0.65 & 1610 & 135 & 9.4 & 0.28 & 5.0 & 1490 & 1210 & 40.7 & 197 & 92.3 \\
\hline
\end{tabular}




$$
\begin{aligned}
& F_{1}=\frac{1}{X_{t}}-\frac{1}{X_{c}}, \\
& F_{11}=\frac{1}{X_{t} X_{c}}, \\
& F_{2}=\frac{1}{Y_{t}-Y_{c}} \\
& F_{22}=\frac{1}{Y_{t} Y_{c}}, F_{66}=\frac{1}{S^{2}}
\end{aligned}
$$

\subsection{Finite Element Analysis}

The results of finite element analysis of composite wheel are compared with those of aluminum alloy wheel. At the same time, the maximum stress layer under each condition is replaced by (8) Tsai-Wu strength criterion for strength verification. It can be found that the strength of composite wheel hub can meet the requirement.

1) Radial load condition

Maximum stress layer $\sigma_{1}=17.07, \sigma_{2}=1.288, \tau_{12}=1.539$. By substituting Formula (8), the calculation result $0.0229<1$, so the strength requirement can be satisfied under this condition. The stress distributions are shown in Figure 1 and Figure 2.

2) Bending load condition

Maximum stress layer $\sigma_{1}=110.5, \sigma_{2}=35.26, \tau_{12}=37.57$. By substituting Formula (8), the calculation result $0.8146<1$, so the strength requirement can be satisfied under this condition. The stress distributions are shown in Figure 3 and Figure 4.

3) Impact load condition

Maximum stress layer $\sigma_{1}=120.4, \sigma_{2}=29.92, \tau_{12}=61.59$. By substituting Formula (8), the calculation result $0.991<1$, so the strength requirement can be satisfied under this condition. The stress distributions are shown in Figure 5 and Figure 6.

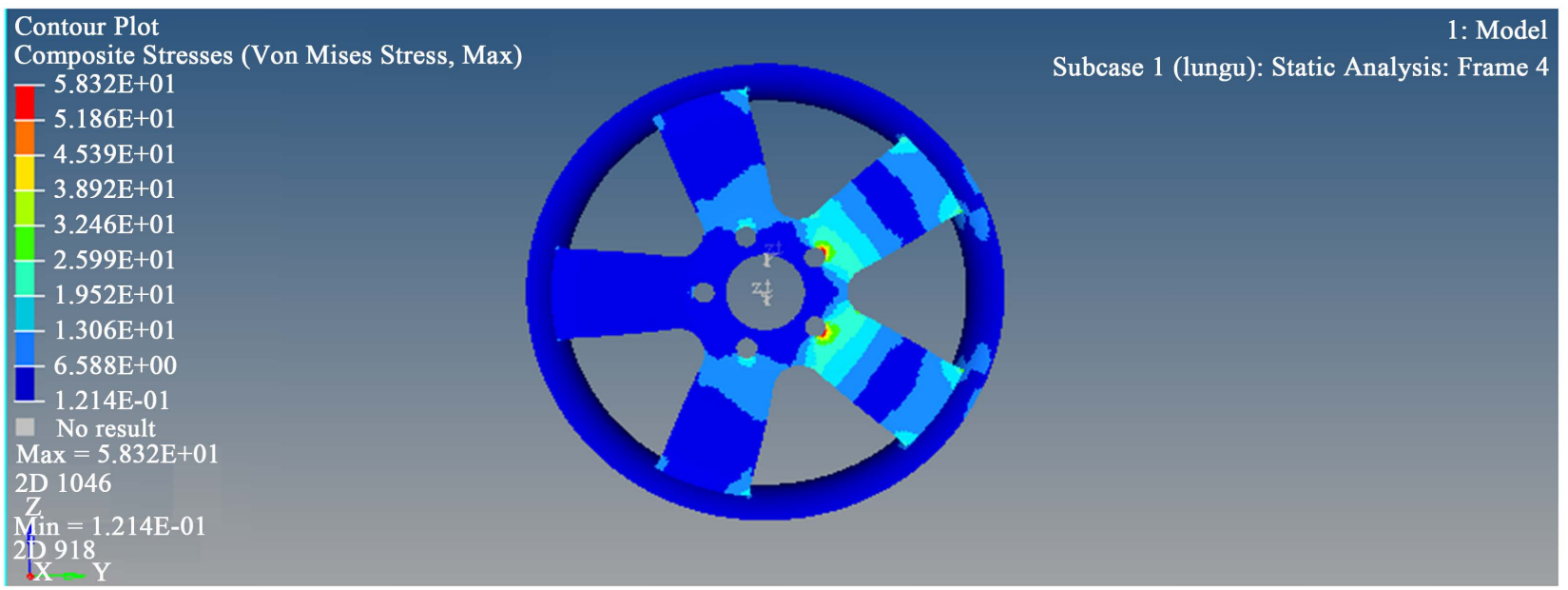

Figure 1. Stress of aluminum alloy wheel under condition 1. 


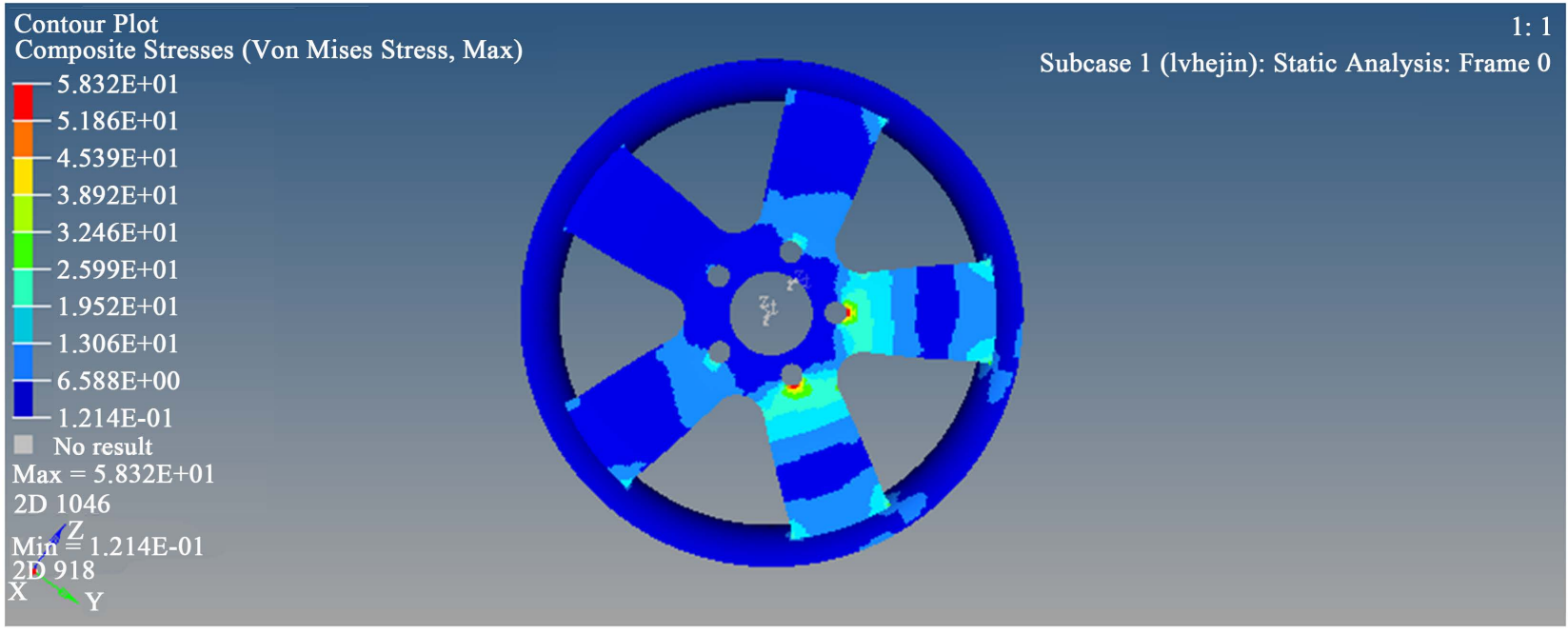

Figure 2. Stress of composite wheel under condition 1.

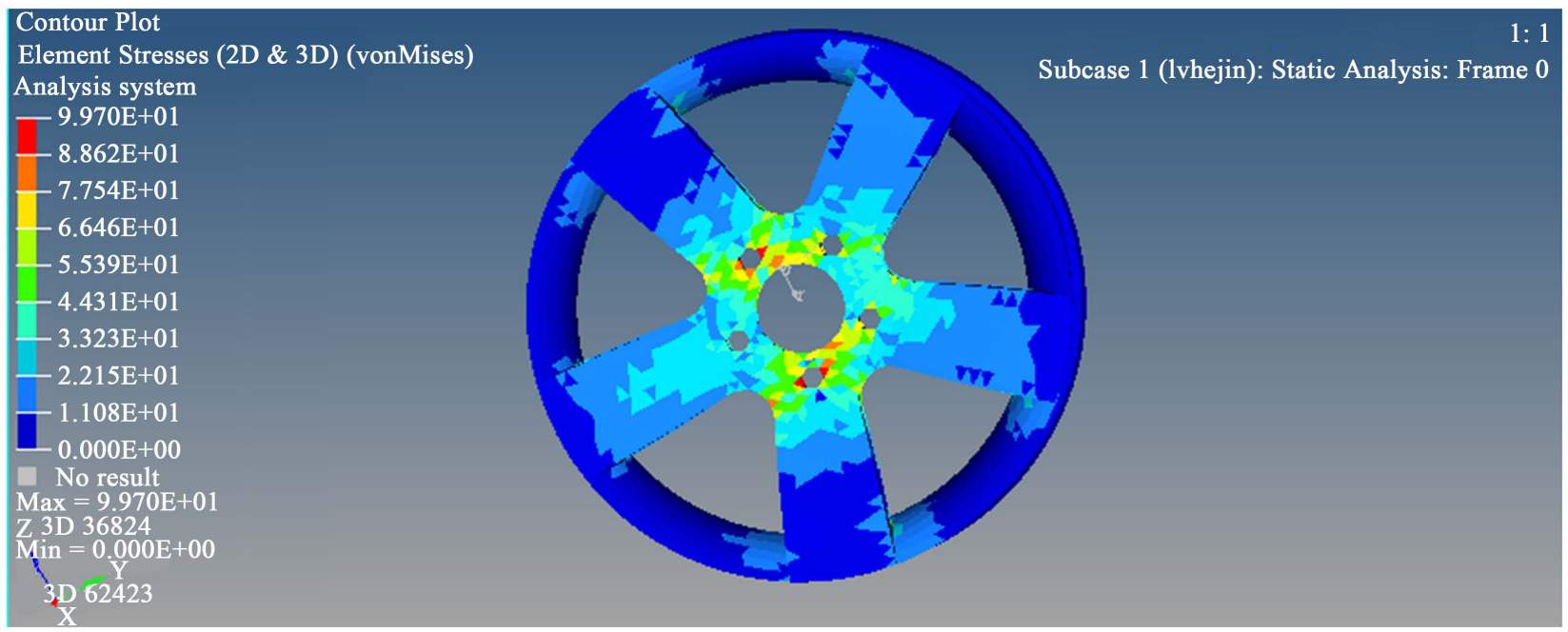

Figure 3. Stress of aluminum alloy wheel under condition 2.

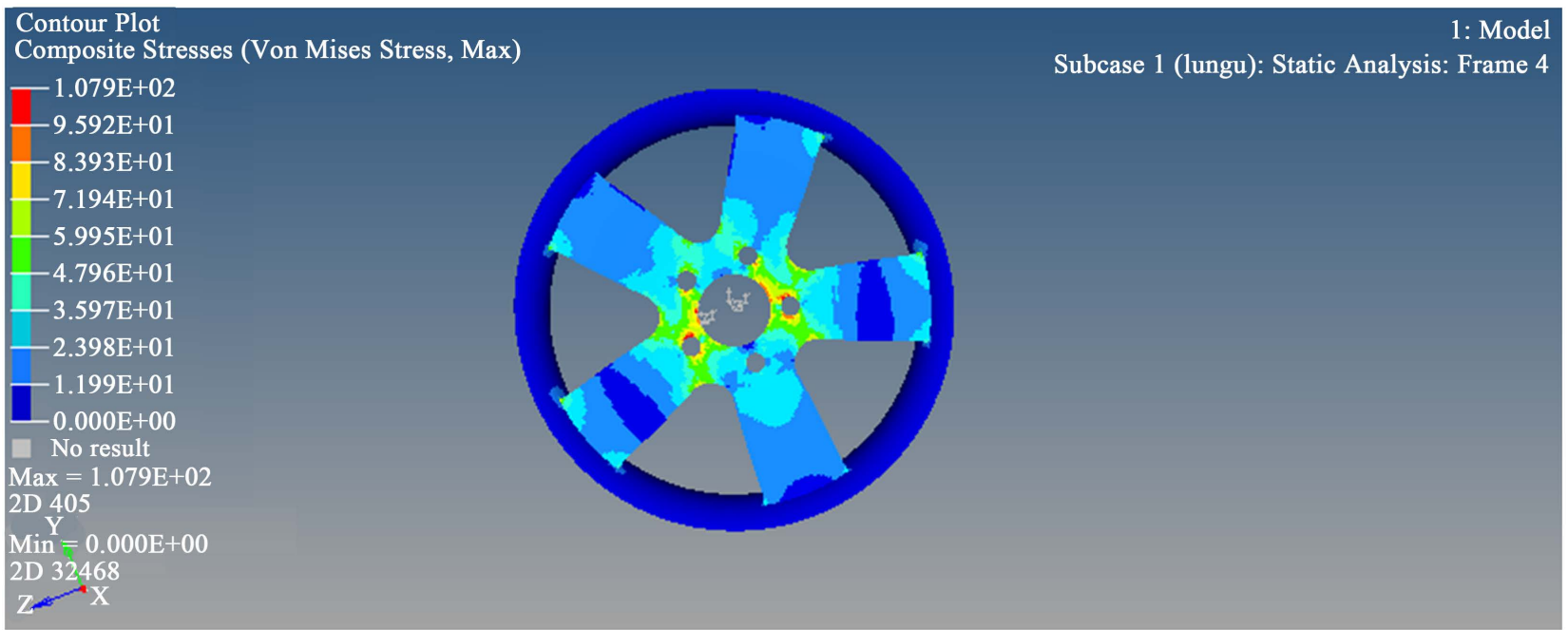

Figure 4. Stress of composite wheel under condition 2. 


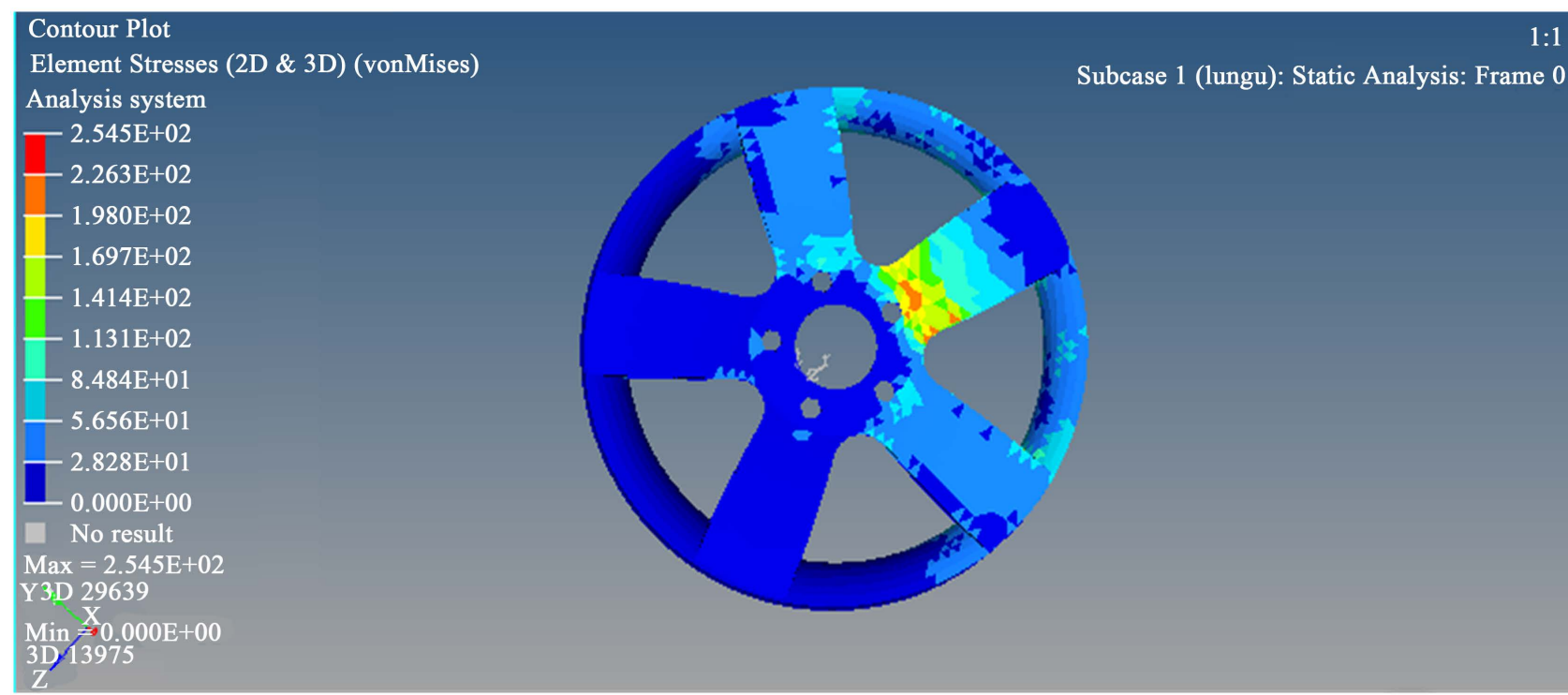

Figure 5. Stress of aluminum alloy wheel under condition 3.

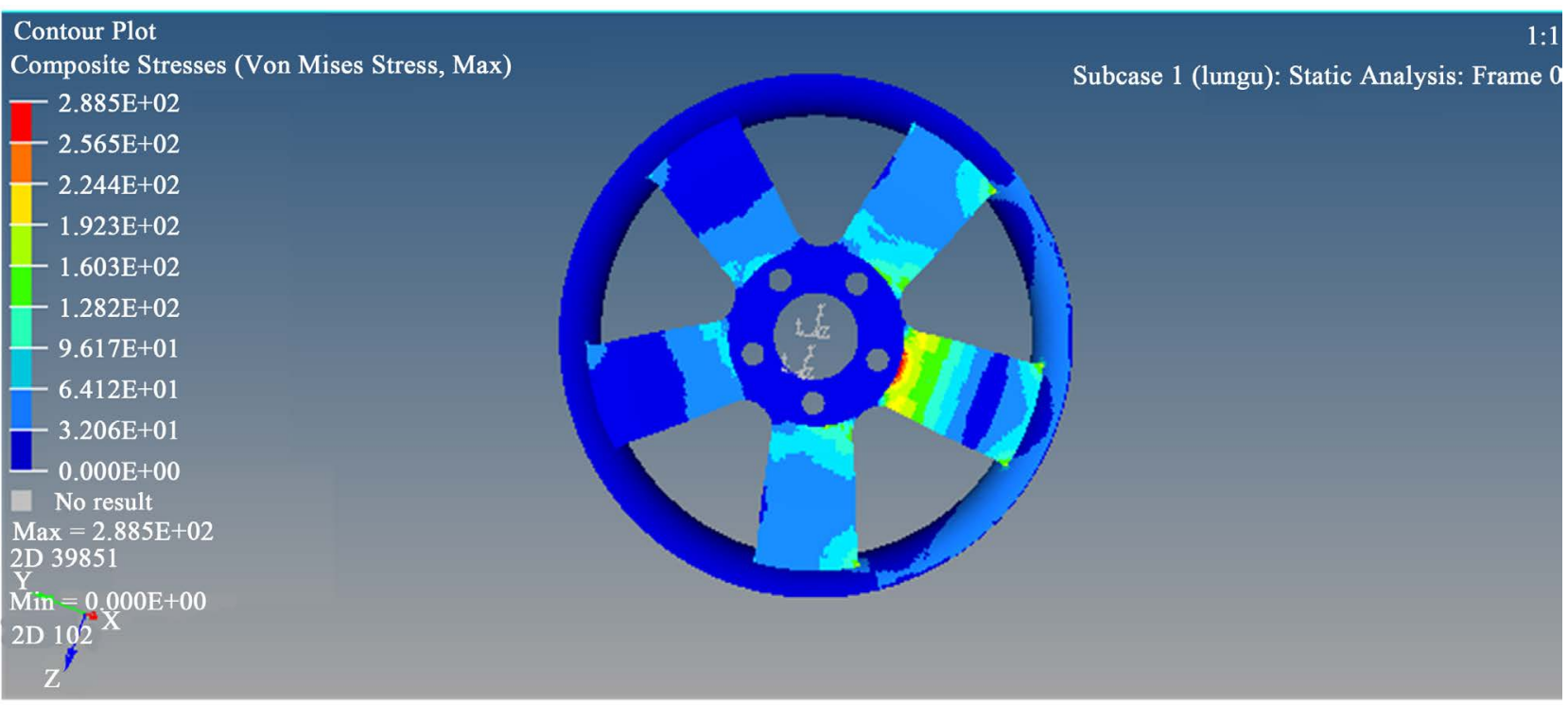

Figure 6. Stress of composite wheel under condition 3.

\section{Conclusions}

1) According to the radial load, bending load and impact load, a finite element model is established to determine the main force position of the wheel hub structure. It has a certain reference to the local shape change and the reduction of stress concentration.

2) Tables 2-4 shows that the maximum stress of composite wheel and Aluminum Alloy are not much different. But because of composite wheel's low density, and the composite wheel weight $11.3 \%$, the ultimate strength is higher than that of aluminum alloy. So in the same condition, the composite wheel is better. 
Table 2. Comparison of finite element analysis results of condition 1.

\begin{tabular}{ccc}
\hline Material & Composite wheel & Aluminum alloy wheel \\
\hline Maximum stress/MPa & 58.32 & 63.49 \\
Maximum strain & 0.0003217 & 0.000786 \\
Maximum deformation/mm & 0.08231 & 0.6628 \\
Main deformation position & Rim & Rim \\
\hline
\end{tabular}

Table 3. Comparison of finite element analysis results of condition 2.

\begin{tabular}{ccc}
\hline Material & Composite wheel & Aluminum alloy wheel \\
\hline Maximum stress $/ \mathrm{MPa}$ & 107.9 & 99.7 \\
Maximum strain & 0.005941 & 0.009495 \\
Maximum deformation/mm & 0.8106 & 0.1513 \\
Main deformation position & Center of spoke & Center of spoke \\
\hline
\end{tabular}

Table 4. Comparison of finite element analysis results of condition 3.

\begin{tabular}{ccc}
\hline Material & Composite wheel & Aluminum alloy wheel \\
\hline Maximum stress/MPa & 288.5 & 254.5 \\
Maximum strain & 0.01624 & 0.03151 \\
Maximum deformation/mm & 6.348 & 5.858 \\
Main deformation position & Rim & Rim \\
\hline
\end{tabular}

3) The analysis of the working condition of the composite wheel hub provides a force reference, and provides the help for the structural optimization design.

\section{References}

[1] Benedyk, J.C. (2000) Light Metals in Automotive Applications. Light Metal Age, 58, 34-35.

[2] Miller, W.S., Zhuang, L., Bottema, J., et al. (2000) Recent Development in Aluminium Alloys for the Automotive Industry. Material Science \& Engineering A, 280, 37-49. https://doi.org/10.1016/S0921-5093(99)00653-X

[3] Wang, X.Y., Liu, X.D., Shan, Y.C., et al. (2016) Lightweight Design of Automotive Wheel Made of Long Glass Fiber Reinforced Thermoplastic. Journal of Mechanical Engineering Science, 230, 1634-1643. (Chinese) https://doi.org/10.1177/0954406215583081

[4] Li, B.P. and Sun, Z.Y., et al. (2016) Research on Molding Process and Property of Automobile Composite Wheel. Material Development and Application, 31, 37-41. (Chinese)

[5] (2015) Strength Simulation on Wheel Made of Long Glass Fiber Reinforced Thermoplasticity Composite under Radial Loading. Computer Aided Engineering, 24, 22-27. (Chinese)

[6] GB/T5334-2005 Passenger Car Wheel Performance Requirements and Experimental Methods. (Chinese) 
[7] GB/T15704-2012 Road Vehicle Light Alloy Wheel Impact Test Method. (Chinese)

[8] Ou, H.G. and Fang, X.J., et al. (2013) RADIOSS Theoretical Foundation and Engineering Application. 58-59

[9] Shang, R., Altenhof, W., Li, N., et al. (2005) Wheel Impact Performance with Consideration of Material Inhomogeneity and a Simplified Approach for Modeling. International Journal of Crashworthiness, 10, 137-150.

https://doi.org/10.1533/ijcr.2005.0333 